Bull. Chem. Soc. Ethiop. 2017, 31(2), 185-199.

ISSN 1011-3924

(c) 2017 Chemical Society of Ethiopia and The Authors

Printed in Ethiopia

DOI: http://dx.doi.org/10.4314/bcse.v31i2.1

\title{
LEVELS OF ESSENTIAL AND NON-ESSENTIAL METALS IN THE RAW SEEDS AND PROCESSED FOOD (ROASTED SEEDS AND BREAD) OF MAIZE/CORN (ZEA MAYS L.) CULTIVATED IN SELECTED AREAS OF ETHIOPIA
}

\author{
Adane Abebe and Bhagwan Singh Chandravanshi* \\ Department of Chemistry, College of Natural Sciences, Addis Ababa University, P.O. Box \\ 1176, Addis Ababa, Ethiopia
}

(Received February 2, 2016; revised November 13, 2017)

\begin{abstract}
The levels of metals in raw maize seeds and its processed foods (roasted seed and bread) collected from Shendi, Finote Selam and Debre Tabor (Ethiopia) were determined by flame atomic absorption spectrometry (major metals) and graphite furnace atomic absorption spectrometry (trace and heavy metals) after wet digestion. The concentration of the metals determined ( $\mathrm{mg} / \mathrm{kg}$ dry weight) were in the ranges in raw seed, roasted seed, and bread: K 1633-1935, 1753-2008, 1589-2036; Na 125-164, 137-190, 160-195; Mg 388-400, 394-411, 378-401; Ca 66.5-104, 118-178, 102-144; Cr 0.17-1.58, 0.18-1.72, 0.18-1.65; Mn 1.04-3.98, 1.09-4.60, 0.52-2.83; Fe $18.0-115,16.5-103,45.3-146$; Co $0.41-0.49,0.50-0.76,0.34-0.75 ; \mathrm{Cu} 0.04-1.32,0.04-2.72,0.05-3.12 ; \mathrm{Zn}$ $61.7-77.6,59.2-83.0,108-116 ; \mathrm{Pb} 0.31-2.59,0.82-3.11,1.55-3.41$; respectively. Nutritionally, the processed maize foods are found to be better sources of minerals than the raw seeds. Maize seed samples from the three areas of Ethiopia are good sources of essential metals. Analysis of variance indicated significant differences in the levels of all the metals among the three samples means except $\mathrm{K}, \mathrm{Mg}$ and $\mathrm{Pb}$.
\end{abstract}

KEY WORDS: Maize (Zea mays L.), Seeds, Processed food (Roasted seeds - Kolo, Bread), Ethiopia

\section{INTRODUCTION}

Maize/corn belongs to the family Poaceae, genus Zea and species Zea mays-corn. Maize/corn is among the most extensively cultivated and consumed cereal crops in the world. It is the main cereal grain as measured by production but ranks third as a staple food, after wheat and rice [1].

More maize is produced, by weight, than any other grain, and almost every country on the Earth cultivates maize commercially for a variety of uses. Currently, the United States, China, Brazil, Mexico, Argentina, India, France, Indonesia, South Africa, and Italy produce $79 \%$ of the world's maize production [2].

The large and sudden rise in maize cultivation in some African countries both in terms of yield and in area planted since the 1980s followed the introduction of different new hybrids from the USA and South America. Its taste has been easily accepted by the local population and, therefore, it could rapidly replace traditional starchy foods like sorghum and millets. About two thirds of all African maize is produced in eastern and southern Africa. South Africa is the largest producer of maize followed by Nigeria [3].

Maize is grown globally from $50^{\circ} \mathrm{N}-40^{\circ} \mathrm{S}$, and from sea level up to $4000 \mathrm{~m}$ altitude. Besides warm sunny weather, corn requires nutrient rich and moist soil. The ideal soil for growing corn is well-drained, preferably a sandy loam. Organic matter such as compost leaves and grass clippings can be added to the soil to improve its overall quality and improve drainage, particularly for heavy clay soil. Like most vegetables, corn grows best in soil with a $\mathrm{pH}$ between 5.8 and 6.8. Maize needs soil with high levels of nitrogen for proper growth and development; thus, additional fertilizer can be added at planting or during the growing season. In the cases

*Corresponding author. E-mail: bscv2006@yahoo.com

This work is licensed under the Creative Commons Attribution 4.0 International License 
when the $\mathrm{pH}$ of the soil is outside the recommended limit, lime or sulfur can be added to adjust the $\mathrm{pH}$ to an ideal level for growing corn [4].

Among cereals, maize accounts for the largest share in total production and the total number of farm holdings involved in Ethiopia. In 2010/11, maize accounted for $28 \%$ of the total cereal production, compared to $22 \%$ for sorghum and $20 \%$ for teff, the second and third most cultivated crops in the country. Maize is the largest and the most productive crop in Ethiopia. Ethiopia is the fourth largest maize producing country in Africa next to South Africa, Nigeria and Egypt [3]. In Ethiopia, maize is widely cultivated in areas with altitudes ranging from 15002200 meters above sea level.

Currently, maize is produced in Ethiopia using both the traditional practices and extension package. The extension package is of a green revolution type characterized by the use of high yielding seed varieties but it involves the use of fertilizers and chemicals. According to World Bank [5] farmers were only achieving on average $60 \%$ of their potential production. The potential for increasing maize production through extensive use of improved seeds is thus high in Ethiopia and is being increased today [6].

Three regional states including Oromia, Amhara and Southern Nations, Nationalities, and Peoples' Region (SNNPR) contribute to $94 \%$ of the total annual production. Oromia region alone contributes $60 \%$ of the country's maize production. West Gojam is leading producer of maize in the country. East Showa, Jimma, East Welega and West Welega zones are the other major producing zones of maize [5].

Both organic and inorganic fertilizers are being used in the country. Organic fertilizers are farm-generated resources such as crop residues, farmyard manure and legumes. Inorganic (modern) fertilizer is a peculiar input the use of which requires improved varieties of maize seeds. Diammonium phosphate and urea are the two most widely adopted inorganic fertilizers in Ethiopia [5].

In developing countries like African countries, large amount of maize produced in every year is used for the direct human consumption. Industrially maize is refined to generate a wide range of products including corn oil, sweetener, corn starch, and ethanol. New bio-products such as amino acids, antibiotics and degradable plastics are increasingly being synthesized using maize as a raw material. Maize is wet-milled to separate the grain into components (starch, oil, protein and fiber) which are then converted into higher value products [7].

Six major staples: maize, teff, wheat, sorghum, barley and enset (false banana), dominate the national food basket in Ethiopia. Maize is the single most important cereal, accounting for 17\% of the per capita calorie intake, followed by sorghum (14\%) and teff (11\%) [8]. Maize dominates rural consumption baskets, more than that of the urban areas. Maize is an important food security crop in Ethiopia, with the cheapest cost caloric source among all major cereals. Despite having the largest number of livestock in Africa, the use of maize grain as animal feed is very limited in Ethiopia [8].

In Ethiopia, maize is mainly used for food and feed purpose. The stover is used for construction and as a domestic fuel in the rural areas of the country, also as food for cattle and other animals. Though maize is mainly used for human consumption, its share in the total calorie intake in Ethiopia is lower as compared to other African countries [9, 10]. In addition to its usage as food in different forms like bread, roasted seed (called kolo), porridge, enjera, and other forms, maize is used as the source of starch for traditional alcoholic beverages production.

The composition of maize endows it with many health benefits. The high fiber content is one characteristic linked to the nutritional benefits of maize. This condition makes it suitable for diets that are made to lose weight and those made with the aim of lowering cholesterol levels. The fiber in whole grains helps to prevent the risk of heart diseases and diabetes, and all its nutrients boost the immune system [11].

Maize, being popular as a food item, is enjoyed by people in various forms, like, whole corn, corn flour, corn starch, corn gluten, corn syrup, corn meal, corn oil, popcorn, cornflakes, etc. 
Apart from satisfying the taste buds of its users, maize is also a good source of vitamins, minerals and dietary fiber [7].

Some studies have been conducted on the levels of essential and non-essential metals of maize in Nigeria [12, 13], Brazil [14], USA [14], China [15] and Turkey [16, 17]. Levels essential and non-essential metals in popcorn and cornflake commercially available in Ethiopia have also been reported [18]. The literature surveys revealed that there are no studies conducted on the levels of metals in maize cultivated in Ethiopia.

Since maize is a staple food for many people in Ethiopia, knowledge of its mineral levels is of particular interest. Hence it is crucial to determine the levels of essential and non-essential metals in maize seed cultivated in Ethiopia. The main objectives of this study were to (i) determine the levels of essential and non-essential metals in raw seeds of maize cultivated in selected areas of Ethiopia: Shendi, Finote Selam and Debre Tabor, (ii) to determine the level of essential and non-essential metals in maize seeds processed food (roasted seeds and bread), (iii) to compare the levels of the metals in maize seeds from three sampling areas and (iv) to compare the levels of the identified metals in maize seeds in this study with the literature values.

\section{EXPERIMENTAL}

\section{Equipments and apparatuses}

Polyethylene bags were used during sample collection and transportation and glass bottles were used while preserving the ground and homogenized samples. Electronic blending device (Foss Knifetec1095, USA) was used for grinding and homogenizing the samples. $250 \mathrm{~mL}$ round bottom flasks fitted with reflux condenser were used with Kjeldahl (UK) apparatus hot plate to digest the dried and powdered maize seed samples. Flame atomic absorption spectrophotometer (Analytikjena: Model ZEEnit700P, VGP AAS, Germany) equipped with deuterium arc back ground connectors and hollow cathode lamps with air-acetylene flame was used for the analysis of the analyte metals. Graphite furnace atomic absorption spectrophotometer (PerkinElmer, AAnalyst 600, USA) was also used in this study.

\section{Reagents and chemicals}

$\mathrm{HNO}_{3} 69-72 \%$ (Scharlau Chemie, European Union, Spain), $\mathrm{HClO}_{4} 60 \%$ (BDH Laboratory Supplies AnalaR ${ }^{\circledR}$, Poole, England) and extra pure $\mathrm{H}_{2} \mathrm{O}_{2} 30 \%$ (Scharlau Chemie, European Union, Spain) were used for digestion of the samples. $\mathrm{La}\left(\mathrm{NO}_{3}\right)_{3} \cdot 6 \mathrm{H}_{2} \mathrm{O} 98 \%$ (BDH Chemicals Ltd, Poole, England) was used to minimize the precipitation of $\mathrm{Ca}$ and $\mathrm{Mg}$ ions in the form of phosphates and sulfates. Stock standard solutions containing $1000 \mathrm{mg} / \mathrm{L}$ of the metals $\mathrm{K}$, Na, $\mathrm{Mg}, \mathrm{Ca}, \mathrm{Cr}, \mathrm{Mn}, \mathrm{Fe}, \mathrm{Co}, \mathrm{Ni}, \mathrm{Cu}, \mathrm{Zn}, \mathrm{Cd}$ and $\mathrm{Pb}\left(\mathrm{BDH}\right.$ Chemicals Ltd Spectrosol ${ }^{\circledR}$, Poole, England) were used for preparation of calibration standards and for the spiking experiments. Deionized water was used for dilution of samples, intermediate and working metal standard solutions prior to analysis and for rinsing glass wares.

\section{Sampling site description}

Debre Tabor. It is a town and a woreda (district) in north central Ethiopia. It is located in the South Gondar zone of the Amhara region, about $100 \mathrm{~km}$ southeast of Gondar and $50 \mathrm{~km}$ east of Lake Tana. It is $103 \mathrm{~km}$ far from Bahir Dar, the capital of the region. According to the road transport authority of Ethiopia, Debre Tabor is about $666 \mathrm{~km}$ far from the capital city Addis Ababa. This town has a latitude and longitude of $11^{\circ} 51^{\prime} \mathrm{N} 38^{\circ} 1^{\prime} \mathrm{E}$ with an elevation of 2,706 meters above sea level [19]. 
Finote Selam. It is a town and separate woreda in western Ethiopia. It is located in the West Gojjam zone of Amhara region. This town has a latitude and longitude of $10^{\circ} 42^{\prime} \mathrm{N}$ and $37^{\circ} 16^{\prime} \mathrm{E}$ with an elevation of 1917 meters above sea level [20]. It is surrounded by Jabi Tehnan woreda. Currently Finote Selam is the administrative center of West Gojjam administrative zone. Finote Selam is about $385 \mathrm{~km}$ in northwest direction of Addis Ababa.

Shendi. It is a town in western Ethiopia. It is located in the West Gojjam zone of the Amhara region. This town has a latitude and longitude of $10^{\circ} 38^{\prime} \mathrm{N}$ and $36^{\circ} 56^{\prime} \mathrm{E}$ with an elevation of 2,050 meters above sea level [20]. Shendi is the administrative centre of Womberma woreda. Womberma is one of the woredas in west Gojjam zone and is one of the surplus producers of cereal crops in the Amhara region.

\section{Sampling}

The possible efforts were made to collect the representative samples of maize seeds from the study areas. About $5 \mathrm{~kg}$ of sample was purchased from ten farmers $(0.5 \mathrm{~kg}$ from each $)$ who were selling maize seed in the open markets in Shendi, Finote Selam and Debre Tabor towns. These ten half kilogram samples from each town were then mixed in to three separate polyethylene plastic bags to get about $5 \mathrm{~kg}$ of one bulk sample for each. Then only a representative portion of about $1.5 \mathrm{~kg}$ samples from each site were packed in the polyethylene plastic bags and were brought to the laboratory for analysis.

\section{Sample preparation for elemental analysis}

The samples were exposed to sun light for drying until constant weight was achieved. A portion of the dried maize seeds were ground using electronic blending device and the powder was transferred to the already prepared plastic bags. Some portions of the samples were roasted using metal pans, get cooled and then got ground using the electronic blending device as it is traditionally done in Ethiopia. This roasted grain in the local term is called "kolo". The roasted seeds were ground using electronic blending device and the powder was transferred to the already prepared plastic bags.

The bread was prepared according to the traditional procedure used in Ethiopia. From the raw maize flour samples bread was made using clay pans. The flour was mixed well with distilled water. The metal pan was heated and then the prepared dough was placed on the pan. The pan with the dough was covered with lid, and after $10 \mathrm{~min}$ the bread was inverted upside down for uniform heat distribution. The bread made was taken off from the pan and allowed to cool. The baked bread was cut in to pieces and exposed to sun light to complete dryness, i.e. until the removal of the water added while baking. The drying process was repeatedly made until a constant weight was obtained. The dried bread sample was crushed in to powder form and made ready in the clean and dry plastic bag until analysis. Similar treatments were made for all the samples from the three sites.

\section{Digestion of the samples}

The basic requirements for sample preparation for analysis are to get an optimum condition for digestion. The optimum condition is the one which require minimum reagent volume consumption, minimum reflux time, clarity of digests, and ease of simplicity [21-26]. In this study, to prepare a clear sample solution suitable for the analysis using AAS, a lot of trials of digestion procedures were made on the maize seed powder using the $\mathrm{HNO}_{3}, \mathrm{H}_{2} \mathrm{O}_{2}$ and $\mathrm{HClO}_{4}$ acid mixtures by varying parameters such as volume of the acid mixture, digestion time and digestion temperature to optimize the digestion procedure (Tables 1 and 2). The acid mixture of 
6:2:2 (6 $\mathrm{mL} \mathrm{HNO}_{3}(69-70 \%), 2 \mathrm{~mL} \mathrm{HClO}_{4}(70 \%)$, and $\left.2 \mathrm{~mL} \mathrm{H}_{2} \mathrm{O}_{2}\right)$, digestion time of 3 hours and digestion temperature of $120{ }^{\circ} \mathrm{C}$ were found the optimal condition for the digestion of $1 \mathrm{~g}$ of samples. These optimum conditions were selected based on clarity of digests, minimum reagent volume consumption, shorter digestion time, and lower temperature applied for complete digestion of the samples.

Applying the optimized conditions $1 \mathrm{~g}$ of homogenized dried and ground maize sample was transferred into $250 \mathrm{~mL}$ round bottom flasks. $10 \mathrm{~mL}$ of the acid mixture with a volume ratio of 6:2:2 (v/v) was added and the mixture was digested on a Kjeldahl digestion apparatus for 3 hours at the temperature of $120{ }^{\circ} \mathrm{C}$. After 3 hours of digestion time the digested mixture was allowed to cool to room temperature without dismantling the digestion set up. At the time of dismantling the setup, about $10 \mathrm{~mL}$ of deionized water was added to the solution and the flask and the lower end of the condenser was rinsed to dissolve the precipitate formed on cooling and to minimize dissolution of filter paper by the digest residue while filtering through Whatman 541 filter paper into $50 \mathrm{~mL}$ volumetric flask containing about $0.67 \mathrm{~g}$ of $\mathrm{La}\left(\mathrm{NO}_{3}\right)_{3} \cdot 6 \mathrm{H}_{2} \mathrm{O}$. The round bottom flasks were rinsed subsequently with deionized water until the total volume reached to the $50 \mathrm{~mL}$ mark. The digestion was carried out in triplicates for each sample.

Table 1. Optimization of volume ratio of the reagents for digestion.

\begin{tabular}{|c|c|c|c|c|l|}
\hline S. No. & $\begin{array}{c}\text { Volume } \\
(\mathrm{mL})\end{array}$ & $\begin{array}{c}\text { Volume ratio }(\mathrm{mL}) \\
\mathrm{HNO}_{3}: \mathrm{HClO}_{4}: \mathrm{H}_{2} \mathrm{O}_{2}\end{array}$ & $\begin{array}{c}\text { Temp. } \\
\left({ }^{\circ} \mathrm{C}\right)\end{array}$ & Time (h) & Observation during volume ratio optimization \\
\hline 1 & 6 & $5: 0: 1$ & 60 & 2 & Yellow solution with too much residue \\
\hline 2 & 7 & $6: 0: 1$ & 60 & 2 & Yellow solution with too much residue \\
\hline 3 & 8 & $7: 0: 1$ & 60 & 2 & Yellow solution with much residue \\
\hline 4 & 9 & $8: 0: 1$ & 60 & 2 & Yellow solution, but relatively lower residue \\
\hline 5 & 10 & $8: 1: 1$ & 60 & 2 & Yellow solution with too much residue \\
\hline 6 & 11 & $9: 1: 1$ & 60 & 2 & Yellow solution with some residue. \\
\hline 7 & 6 & $0: 5: 1$ & 60 & 2 & Dark colored cake like with little liquid \\
\hline 8 & 7 & $0: 6: 1$ & 60 & 2 & Dark and highly turbid solution \\
\hline 9 & 8 & $0: 7: 1$ & 60 & 2 & Dark and highly turbid solution \\
\hline 10 & 9 & $0: 8: 1$ & 60 & 2 & Dark and turbid solution \\
\hline 11 & 10 & $0: 9: 1$ & 60 & 2 & Dark and turbid solution \\
\hline 12 & 11 & $0: 10: 1$ & 60 & 2 & Dark but less turbid solution \\
\hline 13 & 7 & $5: 2: 0$ & 60 & 2 & Light yellow solution with little residue \\
\hline 14 & 8 & $6: 2: 0$ & 60 & 2 & Light yellow solution with very little residue \\
\hline 15 & 9 & $7: 2: 0$ & 60 & 2 & Light yellow solution with very little residue \\
\hline 16 & 10 & $8: 2: 0$ & 60 & 2 & Light yellow solution \\
\hline 17 & 11 & $9: 2: 0$ & 60 & 2 & Light yellow solution \\
\hline 18 & 12 & $10: 2: 0$ & 60 & 2 & Light yellow solution \\
\hline 19 & 8 & $5: 2: 1$ & 60 & 2 & Light yellow solution with little residue \\
\hline 20 & 9 & $6: 2: 1$ & 60 & 2 & Light yellow solution with very little residue \\
\hline 21 & 10 & $7: 2: 1$ & 60 & 2 & Light yellow solution with very little residue \\
\hline 22 & 11 & $8: 2: 1$ & 60 & 2 & Light yellow solution with very little residue \\
\hline 23 & 12 & $9: 2: 1$ & 60 & 2 & Light yellow solution with very little residue \\
\hline 24 & 13 & $10: 2: 1$ & 60 & 2 & Light yellow solution with very little residue \\
\hline $\mathbf{2 5}$ & $\mathbf{1 0}$ & $\mathbf{6 : 2 : 2}$ & $\mathbf{6 0}$ & $\mathbf{2}$ & $\begin{array}{l}\text { A clear light yellow solution with negligible } \\
\text { amount of residue on filtration }\end{array}$ \\
\hline 26 & 10 & $5: 2: 3$ & 60 & 2 & Clear light yellow solution with some residue \\
\hline 27 & 10 & $6: 1: 3$ & 60 & 2 & Clear light solution with some residue \\
\hline 28 & 10 & $7: 1: 2$ & 60 & 2 & Clear light solution with some residue \\
\hline 29 & 10 & $4: 4: 2$ & 60 & 2 & Clear but brown solution \\
\hline
\end{tabular}

The bold font shows the optimized volume ratio. 
Table 2. Optimization of digestion temperature and time.

\begin{tabular}{|c|c|c|c|c|l|}
\hline S. No. & $\begin{array}{c}\text { Total volume } \\
(\mathrm{mL})\end{array}$ & $\begin{array}{c}\text { Optimized volume } \\
\text { ratio }(\mathrm{mL})\end{array}$ & $\begin{array}{c}\text { Temp. } \\
\left({ }^{\circ} \mathrm{C}\right)\end{array}$ & $\begin{array}{c}\text { Time } \\
(\mathrm{h})\end{array}$ & Observation \\
\hline 1 & 10 & $6: 2: 2$ & 60 & 2 & Some yellowish turbid matter \\
\hline 2 & 10 & $6: 2: 2$ & 90 & 2 & The turbid matter decreased \\
\hline $\mathbf{3}$ & $\mathbf{1 0}$ & $\mathbf{6 : 2 : 2}$ & $\mathbf{1 2 0}$ & $\mathbf{2}$ & Clear and light yellow color solution \\
\hline 4 & 10 & $6: 2: 2$ & 150 & 2 & Clear light yellow solution \\
\hline 5 & 10 & $6: 2: 2$ & 180 & 2 & Clear light yellow solution \\
\hline 6 & 10 & $6: 2: 2$ & 210 & 2 & Clear light yellow solution \\
\hline 7 & 10 & $6: 2: 2$ & 120 & $1: 00$ & Yellow solution with some residues \\
\hline 8 & 10 & $6: 2: 2$ & 120 & $1: 15$ & Yellow solution with some residue \\
\hline 9 & 10 & $6: 2: 2$ & 120 & $1: 30$ & Yellow solution with some residue \\
\hline 10 & 10 & $6: 2: 2$ & 120 & $1: 45$ & Yellow solution with some residue \\
\hline 11 & 10 & $6: 2: 2$ & 120 & $2: 00$ & Yellow solution with some residue \\
\hline 12 & 10 & $6: 2: 2$ & 120 & $2: 15$ & Yellow solution with some residue \\
\hline 13 & 10 & $6: 2: 2$ & 120 & $2: 30$ & Light yellow solution with very few residues \\
\hline 14 & 10 & $6: 2: 2$ & 120 & $2: 45$ & Light yellow solution with very few residues \\
\hline $\mathbf{1 5}$ & $\mathbf{1 0}$ & $\mathbf{6 : 2 : 2}$ & $\mathbf{1 2 0}$ & $\mathbf{3 : 0 0}$ & Clear light yellow solution \\
\hline 16 & 10 & $6: 2: 2$ & 120 & $3: 15$ & Clear light yellow solution \\
\hline
\end{tabular}

The bold font (trial 3) indicates optimum digestion temperature and the bold font (trial 15) indicates optimum digestion time. Temp. $\left({ }^{\circ} \mathrm{C}\right)=$ temperature.

Digestion of a reagent blank was also performed in parallel with the maize samples keeping all digestion parameters the same. The digested samples were kept in the refrigerator, until the level of all the metals in the sample solutions were determined.

\section{Determination of metal levels in the samples}

Intermediate $(10 \mathrm{mg} / \mathrm{L})$ standard solutions were prepared from the stock solutions which were $1000 \mathrm{mg} / \mathrm{L}$ in concentration. The intermediate solutions were diluted with deionized water to obtain four working standards for each metal of interest. Then $\mathrm{K}, \mathrm{Na}, \mathrm{Mg}, \mathrm{Ca}, \mathrm{Fe}, \mathrm{Zn}, \mathrm{Cu}, \mathrm{Pb}$, $\mathrm{Ni}$ and $\mathrm{Cr}$ were determined with FAAS equipped with air-acetylene flame system using external calibration curve $\mathrm{Mn}, \mathrm{Cd}$ and Co concentrations were determined using GFAAS. Three replicate determinations were carried out on each sample. All the thirteen metals were determined by absorption/concentration mode and the instrument readout was recorded for each sample and blank solution. The same analytical procedure was employed for the determination of elements in digested blank solutions.

\section{Instrument calibration}

Both the FAAS and GFAAS were calibrated using four series of working standards for each metal of interest. The working standard solutions of each metal were prepared freshly by diluting the intermediate standard solutions. The correlation coefficients of the calibration curves were $>0.997$ which confirmed a very good positive correlation between the change in absorbance and the concentration and were linearly fit. 


\section{Validation of optimized procedure}

The validity of the optimized procedure was assessed by spiking experiments. For this purpose standard solution of $1000 \mathrm{mg} / \mathrm{L}$ was used and intermediate standards of $100 \mathrm{mg} / \mathrm{L}$ and $10 \mathrm{mg} / \mathrm{L}$ were prepared. Thus, spiking was done by classifying the metals in to three groups. In the first group $\mathrm{K}, \mathrm{Na}, \mathrm{Ca}$ and $\mathrm{Mg}$ were grouped; $\mathrm{Zn}, \mathrm{Cu}, \mathrm{Fe}$ and $\mathrm{Mn}$ in the second and $\mathrm{Co}, \mathrm{Cr}, \mathrm{Cd}, \mathrm{Ni}$ and $\mathrm{Pb}$ in the third group. The samples were taken from Shendi raw flour for the first group, from Debre Tabor maize bread for the second group and from Finote Selam roasted seed for the third group. This was to consider the forms and sources of samples.

The spiked and non-spiked samples were digested and analyzed in similar conditions using optimized procedure for sample analysis. Then, the percentage recoveries of the analytes were calculated. The results of recovery analysis were within the range $91.2-109 \%$. The percentage recoveries for the samples were between $100 \pm 10 \%$, which were within the acceptable range for all metals.

\section{RESULTS AND DISCUSSION}

Levels of metals in maize seed samples

Triplicate analysis was made for each metal on triplicate samples and the results are reported as mean \pm SD. Among all the studied metals the level of $\mathrm{Cd}$ and $\mathrm{Ni}$ were below detection limits of the instrument. Results are given in Table 3.

Table 3. Level of metals in $\mathrm{mg} / \mathrm{kg}$ in maize raw seeds, roasted seeds and bread from Shendi, Finote Selam and Debre Tabor.

\begin{tabular}{|c|c|c|c|c|c|c|c|c|c|}
\hline \multirow[t]{3}{*}{ Metal } & \multicolumn{9}{|c|}{ Concentration $(\mathrm{mg} / \mathrm{kg})($ mean $\pm \mathrm{SD})$ of metals in samples from } \\
\hline & \multicolumn{3}{|c|}{ Shendi } & \multicolumn{3}{|c|}{ Finote Selam } & \multicolumn{3}{|c|}{ Debre Tabor } \\
\hline & Raw seed & $\begin{array}{c}\text { Roasted } \\
\text { seed }\end{array}$ & Bread & Raw seed & $\begin{array}{c}\text { Roasted } \\
\text { seed }\end{array}$ & Bread & Raw seed & $\begin{array}{c}\text { Roasted } \\
\text { seed }\end{array}$ & Bread \\
\hline $\mathrm{K}$ & $1688 \pm 49^{\mathrm{a}}$ & $1886 \pm 22^{\mathrm{d}}$ & $1748 \pm 50^{\mathrm{g}}$ & $1754 \pm 46^{\mathrm{a}}$ & $1925 \pm 83^{\mathrm{d}}$ & $1755 \pm 166^{\mathrm{g}}$ & $1784 \pm 151^{\mathrm{a}}$ & $1864 \pm 111^{\mathrm{d}}$ & $1936 \pm 10$ \\
\hline $\mathrm{Na}$ & $163 \pm 1^{\mathrm{a}}$ & $188 \pm 2^{\mathrm{d}}$ & $194 \pm 1^{\mathrm{g}}$ & $126 \pm 1^{b}$ & $139 \pm 3^{\mathrm{e}}$ & $162 \pm 2^{\mathrm{h}}$ & $150 \pm 1^{\mathrm{c}}$ & $155 \pm 2^{\mathrm{f}}$ & $194 \pm 2^{i}$ \\
\hline $\mathrm{Mg}$ & $392 \pm 4^{\mathrm{a}}$ & $402 \pm 11^{\mathrm{a}}$ & $395 \pm 0.7^{\mathrm{a}}$ & $397 \pm 1^{\mathrm{a}}$ & $404 \pm 9^{\mathrm{a}}$ & $395 \pm 6^{\mathrm{a}}$ & $388 \pm 10^{\mathrm{a}}$ & $396 \pm 4^{\mathrm{a}}$ & $394 \pm 0.9^{\mathrm{a}}$ \\
\hline $\mathrm{Ca}$ & $102 \pm 2^{\mathrm{a}}$ & $171 \pm 7^{\mathrm{d}}$ & $139 \pm 5^{\mathrm{g}}$ & $72.0 \pm 3^{\mathrm{b}}$ & $109 \pm 1^{\mathrm{e}}$ & $123 \pm 6^{\mathrm{h}}$ & $67.5 \pm 1^{\mathrm{c}}$ & $124 \pm 6^{\mathrm{f}}$ & $107 \pm 5^{\mathrm{i}}$ \\
\hline $\mathrm{Cr}$ & $0.17 \pm 0.003^{\mathrm{a}}$ & $0.19 \pm 0.01^{2}$ & $0.19 \pm 0.01^{a}$ & $0.23 \pm 0.07^{b}$ & $0.34 \pm 0.004^{c}$ & $0.27 \pm 0.01^{\mathrm{b}}$ & $1.55 \pm 0.03^{\mathrm{d}}$ & $1.70 \pm 0.02^{\mathrm{e}}$ & $1.55 \pm 0.1^{\mathrm{d}}$ \\
\hline $\mathrm{Mn}$ & $2.60 \pm 0.1^{\mathrm{a}}$ & $2.80 \pm 0.05$ & $2.70 \pm 0.13^{\mathrm{g}}$ & $1.23 \pm 0.2^{b}$ & $1.28 \pm 0.2^{\mathrm{e}}$ & $0.65 \pm 0.1^{\mathrm{h}}$ & $3.74 \pm 0.2^{\mathrm{c}}$ & $4.37 \pm 0.2^{\mathrm{f}}$ & $2.42 \pm 0.07^{1}$ \\
\hline $\mathrm{Fe}$ & $112 \pm 3^{\mathrm{a}}$ & $101 \pm 2^{d}$ & $142 \pm 4^{\mathrm{g}}$ & $56.8 \pm 3^{\mathrm{b}}$ & $52.6 \pm 0.6^{\mathrm{e}}$ & $63.4 \pm 2^{\mathrm{h}}$ & $19.5 \pm 3^{\mathrm{c}}$ & $20.0 \pm 2.2^{\mathrm{f}}$ & $46.0 \pm 0.7^{\mathrm{i}}$ \\
\hline Co & $0.48 \pm 0.01^{\mathrm{a}}$ & $0.70 \pm 0.06$ & $0.44 \pm 0.07^{\mathrm{a}}$ & $0.43 \pm 0.2^{\mathrm{a}}$ & $0.58 \pm 0.08^{c}$ & $0.48 \pm 0.02^{\mathrm{a}}$ & \begin{tabular}{|l}
$0.46 \pm 0.02^{\mathrm{a}}$ \\
\end{tabular} & $0.66 \pm 0.10^{b}$ & $0.69 \pm 0.06^{\mathrm{b}}$ \\
\hline $\mathrm{Cu}$ & $1.32 \pm 0.31^{\mathrm{a}}$ & $1.95 \pm 0.77$ & $2.87 \pm 0.25^{8}$ & $0.08 \pm 0.01^{b}$ & $0.05 \pm 0.002^{\mathrm{c}}$ & $0.05 \pm 0.004^{\mathrm{h}}$ & $0.04 \pm 0.001^{b}$ & $0.05 \pm 0.003^{\text {th }}$ & $0.05 \pm 0.004$ \\
\hline $\mathrm{Zn}$ & $61.4 \pm 2^{\mathrm{a}}$ & $77.6 \pm 4^{d}$ & $66.7 \pm 5^{\mathrm{g}}$ & $72.7 \pm 5^{\mathrm{a}}$ & $75.1 \pm 8^{\mathrm{d}}$ & $77.5 \pm 3^{\mathrm{h}}$ & $69.9 \pm 8^{\mathrm{a}}$ & $73.3 \pm 2^{d}$ & $112 \pm 4^{\mathrm{i}}$ \\
\hline $\mathrm{Pb}$ & $1.21=$ & $1 \pm 1$ & $2.60=$ & .5 & $2.71 \pm 0.4^{\mathrm{b}}$ & $2.02 \pm 0.6$ & $1.25 \pm 0.03^{\mathrm{a}}$ & $2.11 \pm 0.5^{\mathrm{c}}$ & $2.04 \pm 0$ \\
\hline
\end{tabular}

The same letter indicated that the values were not significantly different at $\mathrm{p}<0.05$, according to Duncan's multiple range test.

Levels of metals in maize seeds

There is a variation in the metal concentration of macro-essential metals among the maize samples collected from the three sampling areas. The concentration of $\mathrm{K}$ was the highest of all the major metals as shown in Table 3. It was also the highest of all the metals under consideration. It was within the range $1589-2036 \mathrm{mg} / \mathrm{kg}$ dry weight, followed by $\mathrm{Mg}, \mathrm{Na}$ and Ca 303-413, 125-195 and 66.5-178 mg/kg, respectively. That means the concentration profile of macro-essential metals determined in maize seeds was $\mathrm{K}>\mathrm{Mg}>\mathrm{Na}>\mathrm{Ca}$.

Among the sample sites the highest concentration of $\mathrm{K}$ was determined in a sample from Debre Tabor (1633-2036 mg/kg dry weight) followed by Finote Selam (1589-2008 mg/kg) and 
Shendi $(1639-1908 \mathrm{mg} / \mathrm{kg}$ ). In this study the concentration of $\mathrm{K}$ determined by sample sites decreased in the order Debre Tabor $>$ Finote Selam $>$ Shindi. The concentrations of Mg from Shendi and Finote Selam are somewhat the same (388-413 and $389-413 \mathrm{mg} / \mathrm{kg}$ ), but the value obtained from Debre Tabor is slightly lower than both sample sites (303-400 mg/kg). The amount of $\mathrm{Na}$ obtained in the samples from the three sites was as follows: Shendi 161-195 $\mathrm{mg} / \mathrm{kg}$, Finote Selam 125-164 mg/kg and Debre Tabor $149-195 \mathrm{mg} / \mathrm{kg}$. This means that the level of $\mathrm{Na}$ in the sample from Shendi and Debre Tabor are significantly higher $($ at $\mathrm{p}<0.05)$ than that of Finote Selam. The levels of $\mathrm{Ca}$ in the samples were recorded as $100-178 \mathrm{mg} / \mathrm{kg}$, $69.0-129 \mathrm{mg} / \mathrm{kg}$ and $66.5-130 \mathrm{mg} / \mathrm{kg}$ from Shendi, Finote Selam and Debre Tabor samples, respectively. The sample from Shendi is the highest of the three sites in Ca content. The values of $\mathrm{Ca}$ in samples from Finote Selam and Debre Tabor are not significantly different at $\mathrm{p}<0.05$. From Table 3 we can see that $\mathrm{Fe}$ is the highest accumulated trace essential metal measured followed by $\mathrm{Zn}$ and $\mathrm{Mn}$ with concentration ranges $16.5-146 \mathrm{mg} / \mathrm{kg}, 59.2-116 \mathrm{mg} / \mathrm{kg}$ and $0.52-$ $3.98 \mathrm{mg} / \mathrm{kg}$, respectively. It is also clearly seen in Table 3 that the concentration ranges of all the trace metals except $\mathrm{Fe}$ and $\mathrm{Zn}$ overlap each other among the sample sites. The highest concentration of Fe may be attributed to its higher levels in the soil [26, 27].

Levels of metals in the processed food (roasted seeds and bread)

When we see the levels of macro-essential and micro-essential metals in the raw seed, roasted seed and bread in Table 3 the values were in the order roasted seed $>$ bread $>$ raw seed samples for all metals. Thus the processed foods (roasted seed and the bread) are more nutritious than the raw seeds. This is desirable because people consume the processed food. This is due to the fact that during the roasting of seed and backing of bread the volatile components of the raw seed gets evaporated and minerals get concentrated. The level of toxic metal $\mathrm{Pb}$ was also higher in the roasted seed and bread compared to the raw seed. This is also expected but it is undesirable and unavoidable.

\section{Distribution patterns of metals in the samples}

The uptake of metals by plants takes place through different and complex biochemical processes. The uptake processes vary based on the ability of the plants to absorb metals from the soil, the availability of the minerals in the soluble and usable forms, the abundance of particular minerals at the particular areas, the degree of contamination of the soil with heavy metals, etc. The differences in the levels of metals in soil arise mainly due to pollution of the biosphere resulting from the rapid industrialization and modern large scale agricultural activities, i.e. use of different types of fertilizers, pesticides and other chemicals.

The use of sewage sludge, pesticides, irrigation with polluted water and fertilizers on agricultural lands highly affect the quality of food products for humans and animals. The distribution and accumulation of metals in maize seeds are the reflections of the mineral composition of the soil and the degree of mineral pollution of the environment in which the maize plant grows. Therefore, the actual metal concentration of maize seeds vary considerably according to the geographic origin, the use of fertilizers with different chemical compositions and other characterizing features such as quality water for irrigation and also the storage conditions of the products.

If we compare the levels of individual metals by sample site the trend can be shown as follows: Shendi $>$ Finote Selam $>$ Debre Tabor in Fe content. Debre Tabor $>$ Shendi $>$ Finote Selam in Mn content. Shendi $>$ Finote Selam $\approx$ Debre Tabor in $\mathrm{Cu}$ content. Debre Tabor $>$ Shendi $\approx$ Finote Selam in Zn content. Debre Tabor $\approx$ Shendi $\approx$ Finote Selam in the level of Co.

The variations in concentrations of $\mathrm{Co}$ and $\mathrm{Mn}$ are not that much significant and comparable to each other for the three sites. That means the distribution of these metals is invariant in 
comparison to other metals. The variation of Fe by sample sites was the highest among the micro-essential metals and the variation for Co by sample sites is the least as shown in Table3.

\section{Concentration of non-essential (toxic) metals in maize seeds}

According to World Health Organization [28] the dietary exposure to $\mathrm{Cd}$ is estimated to be about $1.2 \times 10^{-4}$ to $4.9 \times 10^{-4} \mathrm{mg} / \mathrm{kg}$ of body weight daily. Intake of dietary Cd should not exceed $0.007 \mathrm{mg} / \mathrm{kg}$ of body weight, per week. However, the levels of $\mathrm{Cd}$ and $\mathrm{Ni}$ in this work were below the instrument detection limits. Using maize seeds from these sites is safe for human consumption and safe from human health problems due to the accumulation of $\mathrm{Cd}$ and $\mathrm{Ni}$ in maize seeds.

$\mathrm{Pb}$ is a major chemical pollutant of the environment, and is highly toxic to man. The values determined for $\mathrm{Pb}$ level in this work are presented in Table 3. As we can see from Table 3 the variations among the sites are comparably small, but the amount of $\mathrm{Pb}$ determined from Finote Selam is slightly higher than both from Shendi and Debre Tabor. The variation for $\mathrm{Pb}$ content in the maize seed by sample site may be attributed to agricultural inputs such as fertilizers herbicides and insecticides containing $\mathrm{Pb}$ as an ingredient. Exposure to contamination by dust particles and particulate matters in the air containing $\mathrm{Pb}$ during storage and transportation by cultivators could be the other causes for the higher values [29].

The variation on the level of $\mathrm{Cr}$ between Shendi and Finote Selam is not significant, but the level in the sample from Debre Tabor is higher. We can compare the differences as Debre Tabor $>$ Finote Selam > Shendi in Cr content.

\section{Comparison of metal levels of the present study with literature values}

Comparison of levels of metals obtained in this study has been made with the investigations made in other countries by other investigators. Different researches were being made by different researchers in different countries on maize seed, but in the Ethiopian case no detail studies were made on the levels of major, trace and toxic metal composition in maize seeds.

For the purpose of comparison, the results of this study and results from different literatures are shown in Table 4. As it is seen from the Table 4, the levels of macro-essential metals determined in this work are in good agreement with other studies done in other countries. The concentration of $\mathrm{K}$ is in the range $3.24-2662 \mathrm{mg} / \mathrm{kg}$, Na in the range $75.8-3230 \mathrm{mg} / \mathrm{kg}, \mathrm{Mg}$ in the range $48.94-1154 \mathrm{mg} / \mathrm{kg}$ and $\mathrm{Ca} 0.61-215 \mathrm{mg} / \mathrm{kg}$ dry weight. The results of this study (K 1589-2036, Na 125-178, Mg 303-413 and Ca 66.5-178 mg/kg) are all in the ranges.

Table 4. Comparison of macro-essential metals concentration, $(\mathrm{mg} / \mathrm{kg}$, dry weight basis) in maize raw seed samples with reported values.

\begin{tabular}{|c|c|c|c|c|c|}
\hline $\mathrm{K}$ & $\mathrm{Na}$ & $\mathrm{Mg}$ & $\mathrm{Ca}$ & Country & Reference \\
\hline 1701 & 536 & 1154 & 68.4 & Turkey & {$[16]$} \\
\hline 2662 & 75.8 & 91.5 & 216 & Turkey & {$[17]$} \\
\hline 1620 & 2600 & 200 & 20 & Brazil & {$[14]$} \\
\hline 1950 & 3230 & 200 & 20 & USA & {$[14]$} \\
\hline $\mathrm{NR}$ & $\mathrm{NR}$ & $248-321$ & $1.2-10.2$ & Nigeria & {$[12]$} \\
\hline $\mathrm{NR}$ & $\mathrm{NR}$ & $\mathrm{NR}$ & $\mathrm{NR}$ & China & {$[15]$} \\
\hline 3.24 & 3.72 & 48.9 & 0.61 & Nigeria & {$[13]$} \\
\hline $1589-2036$ & $125-195$ & $303-413$ & $66.5-178$ & Ethiopia & This study \\
\hline
\end{tabular}

$\mathrm{NR}=$ not reported, $\mathrm{ND}=$ not detected. 
The levels of micro-essential metals in this study and from the literature are shown in Table 5. Also here the values from this study are in good agreement with those from literatures. If we look the values from the literatures [12-17] $\mathrm{Fe}$ is in the range $5.9-159 \mathrm{mg} / \mathrm{kg}, \mathrm{Cr} 0.338-2.38$ $\mathrm{mg} / \mathrm{kg}, \mathrm{Mn}$ ND to $8.4 \mathrm{mg} / \mathrm{kg}$, Co ND to $0.8 \mathrm{mg} / \mathrm{kg}$ and Ni ND to $4.78 \mathrm{mg} / \mathrm{kg}$. The levels of all the metals of this study are in the ranges from the literatures used, i.e. Fe $16.5-146 \mathrm{mg} / \mathrm{kg}, \mathrm{Cr}$ $0.17-1.72 \mathrm{mg} / \mathrm{kg}$, Mn 0.52-3.98 mg/kg, Co $0.34-0.76 \mathrm{mg} / \mathrm{kg}$ and Ni ND are all in the above ranges. In fact the level of $\mathrm{Fe}$ in this study is in a higher range $(16.5-146 \mathrm{mg} / \mathrm{kg})$, compared to only one literature [17] from Turkey $159 \mathrm{mg} / \mathrm{kg}$. The high value of Fe in this study is most probably resulted from the high concentration of $\mathrm{Fe}$ in the soil. Researches in the recent years indicate that Ethiopian soil is high in Fe content, so plants can absorb Fe easily. This could be one reason behind the high value of Fe in Ethiopian maize. [26, 27].

Table 5. Comparison of micro-essential metals concentration, $(\mathrm{mg} / \mathrm{kg}$, dry weight basis) in maize raw seed samples with reported values.

\begin{tabular}{|c|c|c|c|c|c|c|c|c|}
\hline $\mathrm{Cr}$ & $\mathrm{Mn}$ & $\mathrm{Fe}$ & $\mathrm{Co}$ & $\mathrm{Ni}$ & $\mathrm{Cu}$ & $\mathrm{Zn}$ & Country & Reference \\
\hline 2.38 & $\mathrm{ND}$ & 37.9 & $\mathrm{NR}$ & 0.79 & 2.85 & 33.6 & Turkey & {$[16]$} \\
\hline 1.0 & 8.4 & 159 & 0.8 & 0.022 & 3.0 & 28.4 & Turkey & {$[17]$} \\
\hline $\mathrm{NR}$ & $\mathrm{NR}$ & 5.9 & $\mathrm{NR}$ & $\mathrm{NR}$ & 0.46 & 5.0 & Brazil & {$[14]$} \\
\hline $\mathrm{NR}$ & $\mathrm{NR}$ & 8.6 & $\mathrm{NR}$ & $\mathrm{NR}$ & 0.58 & 3.9 & USA & {$[14]$} \\
\hline $\mathrm{NR}$ & $\mathrm{NR}$ & $28.5-59.5$ & $\mathrm{ND}$ & $1.87-4.78$ & $2-10.7$ & $\mathrm{NR}$ & Nigeria & {$[12]$} \\
\hline $339^{*}$ & 4.40 & 28.9 & $6.58^{*}$ & $123^{*}$ & 2.86 & 15.0 & China & {$[15]$} \\
\hline 1.36 & $\mathrm{ND}$ & 8.66 & $\mathrm{ND}$ & 1.04 & 2.05 & 6.69 & Nigeria & {$[13]$} \\
\hline $0.17-1.72$ & $0.52-3.98$ & $16.5-146$ & $0.34-0.76$ & $\mathrm{ND}$ & $0.04-2.72$ & $59.2-116$ & Ethiopia & This study \\
\hline
\end{tabular}

$\mathrm{NR}=$ not reported, $\mathrm{ND}=$ not detected, $*=$ concentration $\mu \mathrm{g} / \mathrm{kg}$, the rest are in $\mathrm{mg} / \mathrm{kg}$.

Table 6. Comparison of toxic heavy metals concentration, $(\mathrm{mg} / \mathrm{kg}$, dry weight basis) in maize raw seed samples with reported values.

\begin{tabular}{|c|c|c|c|}
\hline $\mathrm{Cd}$ & $\mathrm{Pb}$ & Country & Reference \\
\hline $\mathrm{NR}$ & $\mathrm{NR}$ & Turkey & {$[16]$} \\
\hline $\mathrm{ND}$ & 1.5 & Turkey & {$[17]$} \\
\hline $\mathrm{NR}$ & $\mathrm{NR}$ & Brazil & {$[14]$} \\
\hline $\mathrm{NR}$ & $\mathrm{NR}$ & USA & {$[12]$} \\
\hline $\mathrm{NR}$ & $62.5-150$ & Nigeria & {$[15]$} \\
\hline $32.3^{*}$ & $38.2^{*}$ & China & {$[13]$} \\
\hline $\mathrm{ND}$ & 0.32 & Nigeria & This study \\
\hline $\mathrm{ND}$ & $0.31-3.41$ & Ethiopia & \\
\hline
\end{tabular}

$\mathrm{NR}=$ not reported, $\mathrm{ND}=$ not detected,$*=$ concentration in $\mu \mathrm{g} / \mathrm{kg}$

The determination of levels of toxic metals was also carried out in this study and Cd was found to be below detection limit of the instrument. The level of $\mathrm{Pb}$ was found as $0.31-3.41$ $\mathrm{mg} / \mathrm{kg}$, when it is compared with the values in the literature (Table 6) it is lower than that mentioned by Olu et al. [12] in Nigeria $(62.5-150 \mathrm{mg} / \mathrm{kg}$ ) but higher than most others.

\section{Analysis of variance (ANOVA)}

In this study, maize seed samples in three forms were collected from three different areas and the metal levels of each sample was analyzed by AAS. During the processes of sample preparation and analysis a number of random errors may be introduced in each aliquot and in each replicate measurement. The variation in sample mean of the analyte was tested by using one-way ANOVA [30], to examine whether the source for variation was from experimental procedure or heterogeneity among the samples (i.e. difference in mineral contents of soil, $\mathrm{pH}$ of 
soil, water, atmosphere; variation in application of agrochemicals like fertilizers, pesticides, etc. or other variations in cultivation procedures). The source for significant difference between sample means may be due to the differences in mineral contents of soil or $\mathrm{pH}$ of soil which predict the extent of mineral absorption by the maize plant. The results in Table 3, shows the significance of the results between samples and within samples at $\mathrm{p}<0.5$.

From Table 3 one can see that there is significant difference at $95 \%$ confidence level in mean concentrations of all the metals except $\mathrm{K}, \mathrm{Mg}$ and $\mathrm{Pb}$ in all the three sample forms and the means of Co concentration in raw seed and roasted seed as well as the means of $\mathrm{Zn}$ in the form of roasted seed are not significantly different. The source for this significant difference between sample means may be the difference in mineral compositions of the soil or $\mathrm{pH}$ of soil which predict the degree of mineral absorption by plants.

\section{Pearson correlation of metals within maize seed samples}

In this particular study, to correlate the effect of the concentration of one metal over the other metal, the Pearson correlation coefficients were employed. The relations for the three forms of the maize samples are shown in Table 7A-7C.

Table 7A. Pearson's correlation for maize raw seed samples

\begin{tabular}{|c|c|c|c|c|c|c|c|c|c|c|c|}
\hline & $\mathrm{K}$ & $\mathrm{Na}$ & $\mathrm{Mg}$ & $\mathrm{Ca}$ & $\mathrm{Cr}$ & $\mathrm{Mn}$ & $\mathrm{Fe}$ & $\mathrm{Co}$ & $\mathrm{Cu}$ & $\mathrm{Zn}$ & $\mathrm{Pb}$ \\
\hline $\mathrm{K}$ & 1.00 & & & & & & & & & & \\
\hline $\mathrm{Na}$ & 0.54 & 1.00 & & & & & & & & & \\
\hline $\mathrm{Mg}$ & 0.89 & 0.86 & 1.00 & & & & & & & & \\
\hline $\mathrm{Ca}$ & 0.98 & 0.68 & 0.96 & 1.00 & & & & & & & \\
\hline $\mathrm{Cr}$ & 0.77 & 0.15 & 0.36 & 0.63 & 1.00 & & & & & & \\
\hline $\mathrm{Mn}$ & 0.25 & 0.69 & 0.21 & 0.67 & 0.82 & 1.00 & & & & & \\
\hline $\mathrm{Fe}$ & 0.99 & 0.45 & 0.84 & 0.96 & 0.82 & 0.35 & 1.00 & & & & \\
\hline $\mathrm{Co}$ & 0.58 & 0.998 & 0.90 & 0.73 & 0.76 & 0.64 & 0.64 & 1.00 & & & \\
\hline $\mathrm{Cu}$ & 0.96 & 0.75 & 0.98 & 0.996 & 0.56 & 0.25 & 0.93 & 0.25 & 1.00 & & \\
\hline $\mathrm{Zn}$ & 0.70 & 0.98 & 0.96 & 0.82 & 0.77 & 0.51 & 0.63 & 0.99 & 0.87 & 1.00 & \\
\hline $\mathrm{Pb}$ & 0.91 & 0.15 & 0.82 & 0.61 & 0.96 & 0.62 & 0.95 & 0.20 & 0.77 & 0.35 & 1.00 \\
\hline
\end{tabular}

Table 7B. Pearson's correlation for maize roasted seed samples.

\begin{tabular}{|c|c|c|c|c|c|c|c|c|c|c|c|}
\hline & $\mathrm{K}$ & $\mathrm{Na}$ & $\mathrm{Mg}$ & $\mathrm{Ca}$ & $\mathrm{Cr}$ & $\mathrm{Mn}$ & $\mathrm{Fe}$ & $\mathrm{Co}$ & $\mathrm{Cu}$ & $\mathrm{Zn}$ & $\mathrm{Pb}$ \\
\hline $\mathrm{K}$ & 1.00 & & & & & & & & & & \\
\hline $\mathrm{Na}$ & 0.45 & 1.00 & & & & & & & & & \\
\hline $\mathrm{Mg}$ & 0.79 & 0.20 & 1.00 & & & & & & & & \\
\hline $\mathrm{Ca}$ & 0.38 & 0.998 & 0.27 & 1.00 & & & & & & & \\
\hline $\mathrm{Cr}$ & 0.71 & 0.32 & 0.99 & 0.38 & 1.00 & & & & & & \\
\hline $\mathrm{Mn}$ & 0.99 & 0.29 & 0.88 & 0.22 & 0.82 & 1.00 & & & & & \\
\hline $\mathrm{Fe}$ & 0.25 & 0.75 & 0.80 & 0.80 & 0.86 & 0.41 & 1.00 & & & & \\
\hline $\mathrm{Co}$ & 0.77 & 0.92 & 0.21 & 0.89 & 0.09 & 0.65 & 0.43 & 1.00 & & & \\
\hline $\mathrm{Cu}$ & 0.16 & 0.95 & 0.48 & 0.97 & 0.58 & 0.01 & 0.92 & 0.76 & 1.00 & & \\
\hline $\mathrm{Zn}$ & 0.28 & 0.98 & 0.37 & 0.99 & 0.48 & 0.11 & 0.86 & 0.83 & 0.99 & 1.00 & \\
\hline $\mathrm{Pb}$ & 0.94 & 0.13 & 0.94 & 0.06 & 0.90 & 0.99 & 0.56 & 0.51 & 0.12 & 0,05 & 1.00 \\
\hline
\end{tabular}


Table 7C. Pearson's correlation for maize bread samples.

\begin{tabular}{|c|c|c|c|c|c|c|c|c|c|c|c|}
\hline & $\mathrm{K}$ & $\mathrm{Na}$ & $\mathrm{Mg}$ & $\mathrm{Ca}$ & $\mathrm{Cr}$ & $\mathrm{Mn}$ & $\mathrm{Fe}$ & $\mathrm{Co}$ & $\mathrm{Cu}$ & $\mathrm{Zn}$ & $\mathrm{Pb}$ \\
\hline $\mathrm{K}$ & 1.00 & & & & & & & & & & \\
\hline $\mathrm{Na}$ & 0.47 & 1.00 & & & & & & & & & \\
\hline $\mathrm{Mg}$ & 0.99 & 0.50 & 1.00 & & & & & & & & \\
\hline $\mathrm{Ca}$ & 0.88 & 0.010 & 0.87 & 1.00 & & & & & & & \\
\hline $\mathrm{Cr}$ & 1.00 & 0.45 & 0.99 & 0.89 & 1.00 & & & & & & \\
\hline $\mathrm{Mn}$ & 0.36 & 0.99 & 0.39 & 0.13 & 0.34 & 1.00 & & & & & \\
\hline $\mathrm{Fe}$ & 0.67 & 0.34 & 0.64 & 0.94 & 0.68 & 0.46 & 1.00 & & & & \\
\hline $\mathrm{Co}$ & 0.99 & 0.36 & 0.99 & 0.93 & 0.99 & 0.24 & 0.75 & 1.00 & & & \\
\hline $\mathrm{Cu}$ & 0.53 & 0.50 & 0.50 & 0.87 & 0.54 & 0.60 & 0.98 & 0.63 & 1.00 & & \\
\hline $\mathrm{Zn}$ & 0.50 & 0.50 & 1.00 & 0.86 & 0.99 & 0.39 & 0.64 & 0.99 & 0.50 & 1.00 & \\
\hline $\mathrm{Pb}$ & 0.99 & 0.53 & 0.47 & 0.85 & 0.52 & 0.63 & 0.98 & 0.60 & 1.00 & 0.47 & 1.00 \\
\hline
\end{tabular}

The values of Pearson correlation coefficient in Table 7A-7C revealed that there is weak and/or moderate positive correlation between metals with each other except for some metals. The weak correlation indicating that the presence or absence of one metal affects the other metal in a lesser extent. As we can see from the correlation tables there is a very high positive correlation of $\mathrm{K}$ with $\mathrm{Fe}$ in the case of raw seeds, with $\mathrm{Mn}$ in the case of roasted seeds and with $\mathrm{Cr}, \mathrm{Pb}$ and $\mathrm{Mg}$ in the case of bread, $\mathrm{Na}$ with $\mathrm{Zn}$ and $\mathrm{Co}$ both in flour and bread samples. Ca with $\mathrm{Fe}, \mathrm{Cr}$ with $\mathrm{Pb}, \mathrm{Mn}$ with $\mathrm{Pb}, \mathrm{Fe}$ with $\mathrm{Cu}$ and $\mathrm{Pb}$ as well as $\mathrm{Cu}$ with $\mathrm{Pb}$ and $\mathrm{Zn}$ can be mentioned as strong correlations can be seen from the table. These strong correlations may arise from common anthropogenic or natural sources as well as from similarity in chemical properties. Mn show week to medium correlation with most of the metals except the strong relations with $\mathrm{K}, \mathrm{Na}$ and $\mathrm{Pb}$.

\section{Daily intake of metals from maize seed}

Daily intake of metals from maize seed food has been calculated based on the assumption that an average adult person consumes $200 \mathrm{~g}$ dry maize food per day on the average. The amounts of mineral intake by the person from the different forms of maize seed food are given in Table 8 .

Table 8. Comparison of daily intake of metals from maize seed food with recommended daily intake and tolerable upper limit of daily intake of metals.

\begin{tabular}{|c|c|c|c|c|}
\hline Metal & $\begin{array}{c}\text { Concentration in maize } \\
(\mathrm{mg} / \mathrm{kg})\end{array}$ & $\begin{array}{c}\text { Amount of metal per } \\
200 \mathrm{~g} \text { maize consumed }\end{array}$ & $\begin{array}{c}\text { Recommended daily } \\
\text { intake (RDI) }[28,31]\end{array}$ & $\begin{array}{c}\text { Tolerable upper limit } \\
{[28,31]}\end{array}$ \\
\hline $\mathrm{Ca}$ & $66.5-178$ & $13.3-35.6$ & $1000-1200 \mathrm{mg}$ & $2500 \mathrm{mg} / \mathrm{day}$ \\
\hline $\mathrm{Mg}$ & $303-413$ & $60.6-82.6$ & $320-420 \mathrm{mg}$ & $750 \mathrm{mg} / \mathrm{day}$ \\
\hline $\mathrm{K}$ & $1589-2036$ & $318-407$ & $4700 \mathrm{mg}$ & $\mathrm{ND}$ \\
\hline $\mathrm{Na}$ & $125-195$ & $25-39$ & $1500 \mathrm{mg}$ & $2300 \mathrm{mg} / \mathrm{day}$ \\
\hline $\mathrm{Cr}$ & $0.17-1.72$ & $0.03-0.25$ & $25-35 \mu \mathrm{g}$ & $120 \mu \mathrm{g} / \mathrm{day}$ \\
\hline $\mathrm{Cu}$ & $0.04-2.72$ & $0.01-0.54$ & $0.9-2 \mathrm{mg}$ & $10 \mathrm{mg} / \mathrm{day}$ \\
\hline $\mathrm{Fe}$ & $16.5-146$ & $3.3-29.2$ & $10-15 \mathrm{mg}$ & $45 \mathrm{mg} / \mathrm{day}$ \\
\hline $\mathrm{Mn}$ & $0.52-3.98$ & $0.104-0.796$ & $1.8-2.3 \mathrm{mg}$ & $11 \mathrm{mg} / \mathrm{day}$ \\
\hline $\mathrm{Ni}$ & $\mathrm{ND}$ & None & $70-170 \mu \mathrm{g} / \mathrm{kg}$ & $1 \mathrm{mg} / \mathrm{day}$ \\
\hline $\mathrm{Zn}$ & $59.2-116$ & $11.8-23.2$ & $10-15 \mathrm{mg}$ & $40 \mathrm{mg} / \mathrm{day}$ \\
\hline $\mathrm{Cd}$ & $\mathrm{ND}$ & None & $\mathrm{ND}$ & $7 \mu \mathrm{g} / \mathrm{kg}$ body wt$/ \mathrm{week}$ \\
\hline $\mathrm{Pb}$ & $0.31-3.41$ & $0.06-0.68$ & $0.02-3 \mu \mathrm{g} / \mathrm{kg} \mathrm{body} \mathrm{wt}$ & $25 \mu \mathrm{g} / \mathrm{kg}$ body wt/day \\
\hline $\mathrm{Co}$ & $0.34-0.76$ & $0.07-0.15$ & $5-40 \mu \mathrm{g} / \mathrm{day}$ & $0.25 \mathrm{mg} / \mathrm{day}$ \\
\hline
\end{tabular}

$\mathrm{ND}=$ not determined (not established). 
The amount of all major metals $(\mathrm{Ca}, \mathrm{Mg}, \mathrm{K}$ and $\mathrm{Na}$ ) that a person can get is lower than the daily recommended values; this indicates that maize alone cannot be a good source of the major metals needed for the daily requirement for the major metals. Therefore the person must get supplementary $\mathrm{Ca}, \mathrm{Mg}, \mathrm{K}$ and $\mathrm{Na}$ from other sources. The amount of $\mathrm{Mn}$ and $\mathrm{Cu}$ that the man can get is also below the required amount. Hence supplementary diet is needed for these metals too. The amount of iron is very sufficient, for the sample from Shendi but below the required limit for those from the other two sites, so additional source of $\mathrm{Fe}$ is needed for those people in the two sites. The amount of $\mathrm{Zn}$ that a man can get from maize is in the range for those from Shendi and Finote Selam, the amount from Debre Tabor is higher than the RDI, but it is still below the maximum limit. The values for $\mathrm{Co}, \mathrm{Cr}$ and $\mathrm{Pb}$ are all above the allowable limits. Maize in these areas has much higher content of these metals. A man must not consume foods from maize regularly. Since the levels of $\mathrm{Cd}$ and $\mathrm{Ni}$ in samples from the three sites are below the detection limit, it is possible to conclude that, a person is free from the risks of $\mathrm{Cd}$ and $\mathrm{Ni}$ as a result of consuming maize.

\section{CONCLUSION}

An efficient digestion procedure for the determination of metals in the raw maize seed and its processed food (roasted seed and bread) samples was developed and validated through spiking method and a good percentage recovery was obtained $(100 \pm 10 \%)$ for all the metals of interest. The levels of metals in maize seed determined in this study was in the order: $\mathrm{K}$ (1589$2036 \mathrm{mg} / \mathrm{kg})>\mathrm{Mg}(303-413 \mathrm{mg} / \mathrm{kg})>\mathrm{Na}(125-195 \mathrm{mg} / \mathrm{kg})>\mathrm{Ca}(66.5-178 \mathrm{mg} / \mathrm{kg})>\mathrm{Fe}$ $(16.5-146 \mathrm{mg} / \mathrm{kg})>\mathrm{Zn}(59.2-116 \mathrm{mg} / \mathrm{kg})>\mathrm{Mn}(0.52-3.98 \mathrm{mg} / \mathrm{kg})>\mathrm{Pb}(0.31-3.41 \mathrm{mg} / \mathrm{kg})>$ $\mathrm{Cu}(0.04-2.72 \mathrm{mg} / \mathrm{kg})>\mathrm{Cr}(0.17-1.72 \mathrm{mg} / \mathrm{kg})>\mathrm{Co}(0.34-0.76 \mathrm{mg} / \mathrm{kg})$.

From the nutritional point of view processed maize foods are better sources of minerals than raw seed. The non-essential/toxic heavy metal, $\mathrm{Cd}$ and the other trace metal, Ni were found below the detection limits of the instrument. It was concluded that maize seeds from the selected sites accumulated relatively larger amounts of $\mathrm{K}$ and $\mathrm{Fe}$ but low levels of $\mathrm{Cu}(0.04-0.08 \mathrm{mg} / \mathrm{kg}$.

The ANOVA results at $95 \%$ confidence level suggests that there were significant difference in the mean concentration of all metals except for $\mathrm{K}, \mathrm{Mg}$ and $\mathrm{Pb}$ among the sampling areas. These differences could be attributed to the difference in mineral contents of soil or $\mathrm{pH}$ of soil which predict the extent of mineral absorption by maize plants. Generally, the level of essential metals in maize seed determined in this study could be put in the following order $\mathrm{K}>\mathrm{Mg}>\mathrm{Na}$ $>\mathrm{Ca}>\mathrm{Fe}>\mathrm{Zn}$. $\mathrm{Mn}, \mathrm{Co}$ and $\mathrm{Cu}$ are not significantly in different ranges. The non-essential heavy metal, $\mathrm{Pb}$ and $\mathrm{Cr}$ are also not significantly in different ranges. The levels of $\mathrm{Cd}$ and $\mathrm{Ni}$ were below the detection limits of the instrument. Statistical analysis using one way ANOVA indicates that there is significant difference in mean concentration of metals under investigation except $\mathrm{K}, \mathrm{Mg}$ and $\mathrm{Pb}$. This may be attributed to differences in soil composition, use of different fertilizers, pesticides, and may also be resulted from random errors in the experimental processes. The concentrations of $\mathrm{Pb}$ determined in this work were relatively lower than most of the values in the literatures mentioned, but it is higher than the recommended values. This higher value may be due to the anthropogenic sources or from the ingredients of agricultural inputs, like fertilizers, insecticides and herbicides used. These results inform the consumer of the safety of maize seeds and its processed foods grown in Shedi, Finote Selam and Debre Tabor, Ethiopia.

\section{ACKNOWLEDGEMENTS}

The authors are thankful to the Department of Chemistry and the School of Earth sciences, Addis Ababa University, Addis Ababa, Ethiopia for providing laboratory facilities. Financial support from Research and Graduate Programs of Addis Ababa University is gratefully acknowledged. Adane Abebe is also thankful to the School of Earth Sciences of the Addis Ababa University for sponsoring his study. 


\section{REFERENCES}

1. Food and Agriculture Organization (FAO) FAO Food and Nutrition Series, No. 25, (ISBN 92-5-103013-8, FAO code: 80 AGRIS: SO1), Maize in Human Nutrition, FAO: Rome (Italy); 1992.

2. Gwirtz, J.A.; Garcia-Casal, M.N. Processing maize flour and corn meal food products. Ann. N. Y. Acad. Sci. 2014, 1312, 66-75.

3. Macauley, H. Cereal Crops: Rice, Maize, Millet, Sorghum, Wheat in Feeding Africa, International Conference, Dekar, Senegal, 21-23 October 2015.

4. Belfield, S.; Brown, C. Field Crop Manual: Maize, A Guide to Upland Production in Cambodia; 2008.

5. World Bank Africa Development Indicators, World Bank, Washington, D.C.; 2006.

6. Dawit, A.; Wilfred, M.; Nigussie, M.; Spielman, D.J. The maize seed system in Ethiopia: Challenges and opportunities in drought prone areas. Afr. J. Agric. Res. 2008, 3, 305-314.

7. Corn Refiners Association Corn Refiners Association Washington, D.C. www.corn.org, 12th ed.; 2013.

8. Rashid, S.; Getnet, K.; Lemma, S. Maize value chain potential in Ethiopia: constraints and opportunities for enhancing the system, IFPRI, Working Paper; 2010.

9. Reynolds, L. Maize for Food, Feed and Fertilizer, A literature review on multiple uses of maize in mixed farming systems in east and southern Africa, Consultant's Report to ILRI and SLP (System-wide Livestock Programme); 1999.

10. Gebremedhin, B.; Fernandez-Rivera, S.; Hassena, M.; Mwangi, W.; Ahmed, S. Maize and livestock: Their inter-linked roles in meeting human needs in Ethiopia. Research Report 6. ILRI (International Livestock Research Institute), Nairobi, Kenya; 2007.

11. Jimenez-Lopez, J.C. Maize: Cultivation, Uses and Health Benefits in Agriculture Issues and Policies, Nova Science Publishers: ebook, ISBN: 978-1-62081-518-2, 2012.

12. Olu, M.; Olufade, O.I.; Adekoyeni, O.O.; Jimoh, M.O. Evaluation of heavy metal concentration in maize grown in selected industrial areas of Ogun State Nigeria and its effects on urban food security. Int. J. Sci. Technol. Soc. 2013, 1, 48-56.

13. Wegwu, M.O.; Omeodu, S.I. Trace metal contents of selected seeds and vegetables from oil producing areas of Nigeria. Chem. Biodiver. 2010, 7, 1737-1744.

14. Padovani, R.M.; Lima, D.M.; Colugnati, F.A.B.; Rodriguez-Amaya, D.B. Comparison of proximate, mineral and vitamin composition of common Brazilian and US foods. J. Food Compos. Anal. 2007, 20, 733-738.

15. Hongxing, Z.; Yu-Kui, R. Determination of trace elements, heavy metals and rare earth elements in corn seeds from Beijing by ICP-MS simultaneously. E.-J. Chem. 2011, 8, 782786.

16. Musa Özcan, M. Determination of the mineral compositions of some selected oil-bearing seeds and kernels using inductively coupled plasma atomic emission spectrometry (ICPAES). Grasas Y. Aceites 2006, 57, 211-218.

17. Hicsonmez, U.; Ozdemir, C.; Cam, S.; Ozdemir, A.; Erees, F.S. Major-minor element analysis in some plant seeds consumed as feed in Turkey. J. Nat. Sci. 2012, 4, 298-303.

18. Abebe, A.; Chandravanshi, B.S.; Debebe, A. Assessment of essential and non-essential metals in popcorn and cornflake commercially available in Ethiopia. Chem. Int. 2017, 3, 268-276.

19. Encyclopedia Britannica Abyssinia, Encyclopedia Britannica, Vol. 1, 11th ed.; 1911.

20. Places in the world. Available at: http://ethiopia.places-in-the-world.com/11048861-placeshendi.html. Accessed on 13 November 2017.

21. Chen, M.; Ma, L.Q. Comparison of three aqua-regia digestion methods for twenty Florida soils. Soil Sci. Soc. Am. J. 2001, 65, 491-499. 
22. Huang, L.; Bell, R.W.; Dell, B.; Woodward, J. Rapid nitric acid digestion of plant material with an open-vessel microwave system. Commun. Soil Sci. Plant Anal. 2004, 35, 427-440.

23. Wilson, B.; Braithwaite, A.; Pyatt, F.B. An evaluation of procedures for the digestion of soils and vegetation from areas with metalliferous pollution. Toxicol. Environ. Chem. 2005, 87, 335-344.

24. Gaudino, S.; Galas, C.; Belli, M.; Barbizzi, S.; Zorzi, P.; Jacimovic, R.; Jeran, Z.; Pati, A.; Sansone, U. The role of different soil sample digestion methods on trace elements analysis: A comparison of ICP-MS and INAA measurement results. J. Qual. Comp. Reli. Chem. Measur. 2007, 12, 84-93.

25. Demirel, S.; Tuzen, M.; Saracoglu, S.; Soylak, M. Evaluation of various digestion procedures for trace element contents of some food materials. J. Hazard. Mater. 2008, 152, 1020-1026.

26. Wagesho, Y.; Chandravanshi, B.S. Levels of essential and non-essential metals in ginger (Zingiber officinale) cultivated in Ethiopia. SpringerPlus 2015, 4:107; DOI 10.1186/s40064015-0899-5.

27. Mekassa, B.; Chandravanshi, B.S. Levels of selected essential and non-essential metals in seeds of korarima (Aframomum corrorima) cultivated in Ethiopia. Braz. J. Food Technol. 2015, 18, 102-111.

28. Joint FAO/WHO Food Standards Programme. Codex committee on contaminants in foods.Fifth Session. The Hague, The Netherlands, 21 - 25 March 2011.

29. Eick, M.J.; Peak, J.D.; Brady, P.V.; Pesek, J.D. Kinetics of lead absorption/desorption on goethite: Residence time effect. J. Soil Sci. 1999, 164, 28-39.

30. Bereton, R.G. Chemometrics: Data Analysis for the Laboratory and Chemical Plant, John Wiley and Sons: London; 2003.

31. Food and Nutrition Board The Dietary Reference Intakes (DRIs), Institute of Medicine, National Academies: USA; 1997. 